\title{
Application of Microtomography and Petrography Techniques For the Characterization of Porosity and Distribution of Synthetic Carbonatic Rock Minerals Before and After Acidification Processes
}

Katia Galindo ( $\nabla$ katiabotelho4@gmail.com )

Federal University of Pernambuco

Cecília Lins

Federal Rural University of Pernambuco

Leonardo Guimarães

Federal University of Pernambuco

Analice Lima

Federal University of Pernambuco

Katarina Silva

Federal University of Pernambuco

Abraão Nova

Federal University of Pernambuco

\section{Research Article}

Keywords:

Posted Date: February 28th, 2022

DOI: https://doi.org/10.21203/rs.3.rs-1293079/v1

License: (c) (i) This work is licensed under a Creative Commons Attribution 4.0 International License.

Read Full License 


\section{Abstract}

The objective of this work is to physically characterize and analyze synthetic carbonate rocks through microtomography and petrography techniques, focusing on a comparative analysis before and after degradation with a reactive fluid. For this study, physical characterization analysis with computerized microtomography and petrography on the samples before and after the acidification procedure was performed. The petrographic analysis verified an increase in both intergranular and intragranular porosities after dissolution. The microtomography analysis quantified the maximum increase in porosity, from $11.8 \%$ to $41.3 \%$ in the two-dimensional analysis and $31.6 \%$ to $52 \%$ in the three-dimensional analysis of the porous structures. Furthermore, the pores were quantified according to their area, and data was obtained on the orientation of the pores, providing insight into the preferred paths of fluid flow. It was also observed that the microtomography technique was an effective tool for characterizing fractures in the samples before and after dissolution. Such analyses are crucial for the extraction and injection of fluids at high depths due to the mechanical and physical risks arising from the dissolution of minerals as well as changes in pressure, temperature, and saturation, all of which affect the stress state of the reservoir rock.

\section{Introduction}

Energy resources such as water, gas, and oil fill the empty spaces contained in rocks. The knowledge of pore-related features is essential in the investigation of reservoirs. Rock porosity is an important topic of study due to several genetic implications. Since the experimental techniques of porosity analysis allow for a quantitative approximation but do not produce a visualization of the porous framework, petrophysical analysis has motivated the search for new analytical techniques for the study of pores. Petrographic analysis by optical microscopy allows the visualization and quantification of intergranular pores; however, it is restricted to the two-dimensional (2D) space, with the quantification being less representative. Quantitative data related to porosity and pore size distribution in rocks are determined directly in the petrographic lamina and indirectly using gas or mercury injections in pycnometers $\mathbf{s}^{1,2,3}$.

Another technique for the detailed visualization of rock microstructures is microtomography. X-ray computed microtomography $(\mu \mathrm{CT})$ was developed based on the traditional tomography procedure, but with a focus on small sample analysis. It is a non-destructive analysis method that consists of obtaining several micrographic slices and the internal three-dimensional (3D) construction of the samples, thus making it possible to determine the area and volume. This technique has been developed to facilitate analysis inside samples of undisturbed soils and rocks, mainly by evaluating the distribution of pores and minerals. Furthermore, it demonstrates the spatial configuration and nature of samples and how they can influence soil and rock behaviors as well as fluid transport processes.

Through microtomography, 3D qualitative and quantitative data related to the shape, size, distribution, volume, area, and spatial distribution of minerals, as well as pores and fractures on a microscale, can be obtained $4,5,6,3,7,8,9$. The spatial porosity and mineral distribution of geological materials significantly 
influence fluid transport processes. These processes are crucial in projects focused on the extraction and injection of fluids at high depths, due to the increase in mechanical and physical risks arising from mineral dissolution and changes in pressure, temperature, and saturation ${ }^{10}$. These phenomena can damage the rock and, consequently, prevent sustainable exploitation of natural resources ${ }^{11,12,13,14,15}$.

The study of phenomena involving reservoir rocks and their characterization is complex. To investigate rock-fluid interactions, $\mathrm{X}$-ray $\mu \mathrm{CT}$ can be used to gather information on the microstructure of rocks. Several studies have used the X-ray microtomography method for digital image processing, such as the work by ${ }^{13}$, which developed a study of natural and artificially cemented limestone rocks subjected to chemical weathering. Through the petrographic images and microtomography, the internal structures of the samples were analyzed regarding the dissolution of grains caused by contact with the reactive fluid. Using this technique, the authors demonstrated pore connectivity and its quantification before and after weathering of the rock. These results made it possible to identify and quantify both in the natural and artificially cemented rocks the relationship between the micro and macro scales as well as changes in the mechanical behaviors of the samples.

${ }^{16}$ performed experimental studies to estimate changes in stresses and strains of synthetic carbonate rock using an edometric cell with horizontal stress measurements. The authors sought to understand hydromechanical and chemical phenomena that occurred and altered the initial characteristics of the rock. Through X-ray $\mu \mathrm{CT}$ analysis, it was possible to identify fractures inside the samples caused by the application of vertical loads together with the dissolution process, as well as the increase in porosity resulting from the dissolution of the grains. These analyses were crucial to understanding the processes that occurred when rocks make contact with reactive fluids. Acidification of reservoirs by geological storage of $\mathrm{CO}_{2}$ and advanced oil and gas recovery chemically alter reservoir rock.

Another application of the $\mu \mathrm{CT}$ technique can be seen in the work of ${ }^{17}$, which analyzed dissolution in the fractures of carbonate rock when injected with an acidic fluid. One of the criteria examined was the porosity related to loss of mass, which was about $20 \%$ higher after contact with the acidic fluid. This loss of mass resulted in a reduction in the shear strength of the sample by $48 \%$ based on measurements before and after injection. Each experimental procedure was carried out through the analysis of $\mu \mathrm{CT}$ images to quantitatively estimate the dissolution of the rock fracture.

${ }^{18}$ emphasized the importance of experimental test data for the development of simulation algorithms. Such algorithms are used to improve rock characterization analyses via $\mu \mathrm{CT}$, which is crucial for enhancing oil extraction. In the study, it is explained that through data obtained by experiments, it was possible to use as input data for simulations of fluid percolation through samples. Microtomographic images were obtained and a 3D reconstruction of the sample images was provided through the $\mu \mathrm{CT}$ technique. The image capture process improved in reliability, allowing porous connections which were previously simulated to be explored with greater confidence. 
${ }^{19}$ emphasized the importance of the study of carbonate rocks, explaining their relevance in the oil industry, as well as the structural complexity of carbonate rocks and the challenges surrounding their characterization. Thus, analyses were conducted on samples of coquinas from the Morro do Chaves Formation in the Sergipe-Alagoas watershed, located in northeastern Brazil. These samples were analogous rocks from significant Brazilian reservoirs. X-ray computed tomography was used for the 3D characterization of the rock structures, and the self-organizing maps (SOM) neural network was used to segment the tomographic images. According to the developed tests, $\mu \mathrm{CT}$ proved to be a consistent tool for the qualitative and quantitative analyses of heterogeneous porous spaces, evaluating the porosity, connectivity, and representative elemental volume, and served as an aid to the petrographic characterization of the samples.

In the study by ${ }^{20}$, the $\mu \mathrm{CT}$ technique was used to analyze the porous structure and permeability of a rock artificially cemented with Portland cement. The internal distribution system, size, and connectivity of the pores were characterized.

The objective of this work is the physical characterization of synthetic carbonate rocks and their analysis through the techniques of microtomography and petrography, with a focus on comparative analysis of the internal porous structures of rocks before and after degradation with a reactive fluid. These are essential tools for the characterization of rocks since their analysis produces detailed visualizations of the microstructures of porous media.

\section{Methodology}

This section presents the experimental protocols performed as part of this research to represent and understand the variations in physical characteristics of synthetic carbonate rocks. The techniques of microtomography and petrography were employed before and after the samples were subjected to an acid flow. The procedure began with the initial characterization of the synthetic rock samples. Following degradation by the fluid, dissolution tests and analyses of the internal structures of these samples were conducted. The characterization of synthetic carbonate rocks consisted of determining the physical properties of the samples, such as porosity and mineralogical distribution, by $\mu \mathrm{CT}$ (analyzed using X-ray Computed Tomography Laboratory [LTC-RX] tomography equipment) and analysis of petrographic slides (analyzed using MEV equipment, electronic microscope of the scan, and a Nikon Eclipse POL) before and after injection of the reactive fluid.

\section{Synthetic Carbonate Rock}

Limestone sedimentary formations are predominantly composed of cementations of carbonate fragments, which are made up of ooids, shells, and reefs. The primary material that comprises synthetic rocks is Halimeda (shell remains), as shown in Figure 1. Synthetic rocks were produced in the laboratory following the experimental protocol of Galindo et al. (2021) and were used in this research to represent and understand the influence of the degradation process on their mechanical, hydraulic, and chemical 
properties. In addition, the behavior of reservoir rocks subjected to chemical attacks from synthetic samples is frequently studied because control of their characteristics is straightforward. Table 1 shows the percentages of materials that comprised the test samples and Figure 2 shows the synthetic rocks produced and used in this research.

To understand the microscopic changes that occurred after contact with fluids, the synthetic samples were developed to achieve mechanical characteristics similar to those of soft natural rocks. Table 2 describes the values of porosity $(\varnothing)$, void index (e), unconfined compressive strength (UCS), tensile compression $(\sigma t)$, and modulus of elasticity $(E)$ of the synthetic samples.

\section{Computerized Microtomography}

One of the analysis methods used to study the internal characteristics of the materials was $\mu \mathrm{CT}$. According to ${ }^{22}$, this non-destructive method involves hundreds of microtomographic cross-sections, which produce internal 3D visualizations of the material under study and quantify volume and area data. It is a technique that measures variations in the density and atomic number of materials through the absorption of radiation emitted on the material.

The spatial arrangements of the porosity and mineral distribution directly affected transport processes in the samples. Thus, the $\mu \mathrm{CT}$ technique was a useful tool for the 3D characterization of the spatial mineral distribution of the geological samples. Using this method, high-resolution analyses were performed and, consequently, visualization of detailed microstructures were obtained $23,24,25,26$. To characterize the samples using $\mu \mathrm{CT}$, analysis of their internal matrices was conducted, which provided information related to pore size and distribution within the samples. Information was also extracted about the sphericity of the pores, which was compared to a perimeter sphere, as well as the spatial position of pores in the matrix $^{27}$.

The material was irradiated from various angles (Figure 3). Thus, several 2D projections were captured by the charge-coupled device (CCD) camera. Each angle provided a new projection. The reconstruction algorithm was used to analyze the projections and generate a set of slices that were stacked, which provided a 3D image of the verified material ${ }^{18,28}$.

Given the non-destructive nature of the $\mu \mathrm{CT}$ analysis method, this process was conducted before the experimental procedures. The rock samples were forwarded for $\mu \mathrm{CT}$ analysis to compare their porosity data before and after the chemical attack. Scanning was performed at the LTC-RX at the Nuclear Energy Department (DEN) of the Federal University of Pernambuco (UFPE). The microtomography equipment was Nikon's XXT H 225 ST, which used a tungsten tube as the X-ray source with a maximum energy of $225 \mathrm{kV}$ and $1001 \mu \mathrm{A}$, as shown in Figure 4. The samples were mounted such that the X-ray beams were perpendicular to the axis of the cylindrical steel support. A $150 \mathrm{kV}$ and $200 \mu \mathrm{A}$ energy source with a 0.5 $\mathrm{mm}$ copper filter was used to scan the images. According to ${ }^{29}$, this configuration produces images with a satisfactory contrast between the pores, matrix, and rocks. 
The programs CT PRO 3D XT 3.0.3 (for image reconstruction) and VG Studio (for treatment of the reconstructed image) were used for pre-processing of the images. The rock samples received around 1200 slices and were exported from CT PRO in TIFF format with the appropriate filters (i.e., Gauss filter) for analysis.

Tomography images were also utilized to examine porosity. A methodology to determine the porosity of soils and rocks was developed by a research group of the Soil Image Laboratory at the University of Guelph (Canada) and a group of the LTC-RX of the DEN at the Federal University of Pernambuco (Brazil). For this analysis, the CTofSoil plugin from the image j program was used. Analysis of the gray level scale in X-ray tomographic images has a partial volume effect called mixed voxels, in which the value is the average of the soil, air, and water interface. Due to limitations, these phases usually overlap each other $29,30,31,32$.

Image analysis began by using the pore voxel extraction (PVE) tool of the image $j$ program because it extracts similar voxels to determine the phase of the figures. Histograms were then identified in which each peak represented a phase to which the voxels belonged. After identifying the peaks (solids and pores), the slice segmentation step began during which the phases of interest in the image were addressed. Finally, using the Image-Adjust-Threshold command, slice binarization was applied (Figure 5), and the CTofSoil plugin command Large Bitwidth Thresholding was used to differentiate pores from non-pores. Thus, the internal structure of the samples could be visualized using the $3 D$ Viewer plugin.

To differentiate the interfaces of the images and determine the porosity, the methodology of ${ }^{29}$ was followed. The plugin Particle Analyze was used to characterize the pores in detail and perform various levels of analysis. The values used in the $P A$ were 0 - 8 voxels for micropores, 9 - 1x104 voxels for mesopores, and greater than $1 \times 104$ for macropores ${ }^{33,29}$. The determining the voxels, they were converted to volumes (Equation 1). To calculate porosity, a ratio between the micro, meso, and macropore data and the total volume of the sample $(\mathrm{Vt})$ was determined, which is the sum of all voxels (converted to volume) in the image (Equation 2).

$\mathrm{V}=\mathrm{N}_{\mathrm{VOXELS}}(\delta)^{3}$

$P(\%)=\frac{v_{p}}{v_{t}} 100$

The orientation of the pores is an important property to be explored during rock analysis and was verified using microtomography images. The pore orientation arrangement relates information about the rock structure, such as properties related to stiffness and permeability time anisotropy used in fluid flow analyses. According to 34,35 , one method to determine pore orientation is to apply an ellipse to the image that best represents the region of the detected pore and obtain the orientation of its longest axis (Figure 6). Accordingly, this procedure was performed for each of the pores identified in the image, as shown in Figure 7. This simplified the morphological representation of the pores through a geometric approximation. The information generated from the pore ellipse coordinates defined the pores that would 
be used for the orientation analysis, which quantified the direction of the dominant axis of the pores individually. This analysis can indicate the preferred axis for fluid flow.

\section{Petrographic Microscopy}

Petrographic microscopy was performed with a petrographic microscope (Nikon Eclipse POL) from the cathodoluminescence laboratory of the geology department at UFPE (Figure 8a). The procedure for this analysis consisted of extracting a thin sheet with a thickness of 35 micrometers of the rock to be analyzed (Figure $8 \mathrm{~b}$ ) and identifying the existing minerals. According to ${ }^{36}$, scanning electron microscopy (SEM) is a tool capable of producing high-resolution images and, depending on the method of image generation, it is possible to visualize the structure with a 3D appearance.

The petrographic microscope is an instrument of fundamental importance in geological studies, whether for studies of reservoir rocks in the search for oil and gas or the classification of metamorphic grades. According to 37,36 , it is an inexpensive tool for quickly predicting the mechanical behavior of rocks. Thus, this procedure was applied to analyze the loss of minerals that occurred as a result of degradation.

\section{Rock Acidification Test}

The synthetic samples used for this work were composed of a carbonate material (Halimeda), quartz sand, and Portland Ari cement. To subject the synthetic rock samples to a reactive fluid, oedometer tests were performed using a modified edometric cell with horizontal stress measurements (Figure 9). Highresolution strain gauges were installed in the middle of the confinement ring of the edometric cell to measure horizontal displacements. For measurements of the vertical displacements, the displacement transducer for linear measurement (LVDT) was used. The samples used for the dissolution test were 6.5 $\mathrm{cm}$ in length and $7.0 \mathrm{~cm}$ in diameter.

Figure 10 shows the dissolution test scheme. The methodology was composed of the loading and dissolution phases. In the loading phase, vertical loads of 150,300 , and $400 \mathrm{kPa}$ with a duration of 1 hour were applied. Then, dissolution began with the fluids of the acetic acid solution at a flow pressure of $12 \mathrm{kPa}$ for approximately 12 hours, totaling 15 liters of solution injected through the synthetic rock. During the test, $\mathrm{pH}$, permeability, and vertical and horizontal displacements were measured. The acid solution was collected for every $200 \mathrm{ml}$ of percolated fluid, and the $\mathrm{pH}$ was measured using the $\mathrm{pH}$ meter throughout the test.

The dissolution test used an acetic acid solution (chemical formula $\mathrm{C}_{2} \mathrm{H}_{4} \mathrm{O}_{2}$ ) with a concentration of $10 \%$, viscosity of $1.22 \mathrm{mPa} \cdot \mathrm{s}$, density of $1.049 \mathrm{~g} / \mathrm{cm}^{3}, \mathrm{pH}$ of 2.8 , and permeability of $1.02 \times 10^{-5} \mathrm{~cm} / \mathrm{s}$. The microscopic characterization analyses of the samples were completed before and after the experimental degradation procedure. Details of the methodology for the dissolution of rocks as well as the output data are described by ${ }^{21}$.

\section{Results And Discussions}


In this section, results are presented for the experimental synthetic carbonate rock study to understand the physical changes that occurred after the rock was degraded with an acid flow. A general characterization of the samples' petrographic structure was conducted as well as a comparison of the structures before and after dissolution. The X-ray microtomography followed the 2D analysis of the samples, resulting in the quantification of the porosity and 3D analysis of the rocks' structure. In addition to quantifying the porosity, the orientation of the pores in the rock structure was verified and indicated anisotropic permeability.

\section{Petrographic Microscopy}

\section{a) Petrographic characterization of thin laminae of synthetic rock samples}

Observations from the mesoscopic scale samples (hand samples) are shown in Figure 11. The samples consisted of an aggregate of minerals cemented by Portland Ari cement, the composition of which has a high percentage of limestone and some oxides. Thus, minerals such as calcium carbonate polymorphs, quartz, feldspar, and minerals from the oxide group were observed in the samples.

Calcium carbonate polymorphs occurred in the hand samples as rounded, white grains with coarse sand to silt granulations. In the hand samples, skeletal grains were observed, such as the shells of gastropods, bivalves, sea urchin spikes, and fragments of a green algae group, identified as Halimeda. Quartz occurred as rounded, medium to fine sand grains that were white to transparent in color, and usually exhibited a surface-altering film of iron oxide around the grains. The feldspar grains, on the other hand, have a shape with regular faces, defined by their two preferential breaking planes, or property called cleavage (the tendency of minerals to break up along parallel planes). They were elongated crystals, with a reddish cream color and medium to fine sand granulation (Figure 11).

Microscopic features were observed using the petrographic microscope (Nikon Eclipse POL). The framework grains formed predominantly punctual and secondarily concave-convex contact between the grains. There was a predominance of carbonate grains (70\%) compared to the siliciclasts (20\%) and oxides $(10 \%)$. At parallel nicols, the carbonate grains were yellowish-white to transparent, and, under crossed nicols, they presented a high interference color characteristic of calcium carbonate, aragonite, and calcite polymorphs ${ }^{39}$. Skeletal grains, mainly fragments of the green algae group Halimeda, indicated by its characteristic internal structure, were also observed under the petrographic microscope, as shown in Figure $12^{39}$. Quartz and feldspar grains were transparent to parallel nicols and displayed a gray to orange interference color under crossed nicols (Figure 8). Oxides were opaque in transmitted light microscopy. The cement used as a binding agent had a brown color to parallel nicols.

Cathodoluminescence is the luminosity caused by the phenomena of fluorescence and phosphorescence and is emitted by the luminogenic centers of minerals bombarded by an electron beam. Analysis was performed using the same procedure with the microscope model Mk 5; however, using the cathodoluminescence technique ${ }^{40}$ during the petrographic study of the synthetic rock samples, carbonate grains associated with Halimeda algae were luminescence activators. Thus, the carbonate grains 
demonstrated a characteristic reddish luminescence. Siliciclastic grains, such as quartz and feldspar, exhibited a blue luminescence. The cement used as a binding agent in the synthetic sample showed several luminescence colors, such as blue, yellow, and red, which may indicate the heterogeneous nature of the composition of the cement used (Figure 13a and b).

\section{b) Petrographic analysis of synthetic rocks before and after degradation}

The synthetic samples had a primary porosity associated with empty spaces both inside and between the grains. Comparing aspects before and after degradation, the primary porosity increased after the passage of the fluid through the synthetic rock. This increase was associated with the inter and intragranular voids, as well as the creation of pores by degradation of the carbonate grains. The difference in the structure of the sample is highlighted in Figures $14 \mathrm{a}$ and $14 \mathrm{~b}$, where the pores are represented by black shading, as well as in Figures $15 \mathrm{a}$ and $15 \mathrm{~b}$, where the pores are represented by blue shading and indicated by the green arrow. The carbonate grains at parallel nicols were yellowish-white to transparent, and under crossed nicols, they presented a high interference color characteristic of calcium carbonate, aragonite, and calcite polymorphs ${ }^{39}$. Skeletal grains were also observed under the petrographic microscope, mainly Halimeda fragments indicated by their characteristic internal structure.

An important feature observed during the petrographic analysis was the appearance of intraparticle porosity due to fluid reactivity, as shown in the enlarged image of Figure 16a. In Figure 16b, several intraparticle pores by a porosity inside the green algae (Halimeda) are displayed. Another aspect observed was related to cracks in some quartz minerals; as a result of the vertical stress applied to the rock samples, the minerals broke (Figure 16c). Even though the constituent nature of the quartz minerals was considered to be inert to weathering, the final conditions to which these minerals were subjected caused changes in their structures.

\section{X-Ray Microtomography}

\section{a) Characterization of synthetic rocks before and after acidification tests}

The 2D computed tomography images (Figure 17) made it possible to observe the increase in porosity that was detected by petrography. An increase in the number of black pixels (representing the pores) between Figures 17a and 17b and red pixels between Figures 17c and 17d can be observed. Thus, there was an increase in the number of pores after the degradation of the samples. By comparing the two samples, it can be verified that the samples degraded with the injection of acidic fluid. The tomography analyses demonstrated that there was a significant increase in the number of pores, indicating that the passage of acidic fluid through the samples caused the dissolution of carbonate minerals that existed in the samples.

A zone was selected in the middle of the main section of the sample to visualize the spatial structure of the pores as well as to better quantify, analyze, and compare microstructural changes. These changes were attributed to fluid flow, as shown by the representation of the rocks' study volume in Figures 18a 
(rock sample before dissolution) and 18b (rock sample after dissolution). From the area in the middle of the sample, a 3D construction of the pore disposition and quantification was generated. The structure was uniform and had isolated pores, as shown in Figure 19a, which represents the distribution of pores in the rock before dissolution. The procedure required binarization of the images; therefore, the accuracy of the results was partially dependent on the user's ability to define the most reasonable threshold level to separate the voids from the solids. After the interaction of the rock with the fluid, the dissolution of soluble minerals occurred and, as a consequence, the pores increased. Figure 19b shows the increase in pore disposition as a result of this degradation.

The porosity values calculated with the standard weighting method (Table 3 ) are summarized using histogram comparatives along with those determined by $\mu \mathrm{CT} 3 \mathrm{D}$ imaging, $\mu \mathrm{CT} 2 \mathrm{D}$ imaging, and laboratory analyses. Since the 2D tomography image analysis methods did not account for all pores, the estimated values were lower compared to the other analysis techniques.

Quantification of the sample porosity was analyzed through the reconstruction of CT images, which is a non-destructive technique that takes into account the absolute porosity of the samples by quantifying both connected (permeable) and non-connected (closed) voids. Notably, this is an estimated value and, according to ${ }^{29}$, there is a limitation when porosity values are obtained through image analysis when the porosity is lower than the voxel of the analyzed image. Thus, the analysis and quantification of pores via $\mathrm{CT}$ is a more effective tool since it considers the precision of the internal geometric structure of rock samples. However, there is no standard for this methodology, since the materials, resolution of equipment, and filters can vary.

After the pores were counted, morphometric properties were processed based on the area and orientation of the pores. This information was important for understanding the porous structures that comprised the rock samples and made it possible to better understand certain attributes of the rocks, such as compressibility, strength, and permeability $41,42,43,44,45,46,47,48,49,50$. Table 4 shows the behavior of the porosity distribution quantification according to the size of the analyzed particles. The image dimensions designate the quality by the number of pixels $(x, y)$ and analyzed slices $(z)$. Taking as a reference the distribution of pores by particle size, the number of large pores was more representative after acidification with the degradation that occurred in the samples. This implies that the grains that were susceptible to degradation were dissolved, which is attributed to the effect on the enlargement of both existing and new pores.

Figure 20 compares the arrangement of the pores and analyzes the preferential path of large pores along the height of the plane of the $x, y$, and $z$ axes. The $x y$-plane corresponds to the height of the sample and, in this plane, it is possible to observe that acidification (i.e., the increase in the number of pores) is more expressive in the center of the sample. The xz-plane is one of the lateral planes, which also displays an increase in the number of pores in the center of the sample. In the yz-plane, in addition to the increase in the number of pores in the center, there is an increase on the side, which can be explained by a large pore 
that dissolved on the side of the sample. While analyzing pore arrangement before acidification, pore conduct was uniform.

After inspecting the images, data were generated representing the frequency of pores according to their area. It was essential to account for the area of each pore to acquire the pore size distribution and understand the porous structure that comprised the rock sample. Based on the analysis of the pore areas of the rock samples before and after degradation (Figure 21), the frequency distribution of the pores increased after degradation (i.e., the pore size increased along with the appearance of new pores).

Thus, in the analysis of pore orientation in the xy-direction (i.e., sample height), as shown in Figure 22, the orientation of the pores was typically higher close to $90^{\circ}$, with maximum frequency values of 800 and 175,000 for samples before and after degradation, respectively. There was also a high frequency at $45^{\circ}$ and $175^{\circ}$, which indicated the fluid path. In addition to the appearance of peaks in Figure $22 \mathrm{~b}$, the orientation tended to be uniform.

When the pores exhibited a horizontal (sloping) orientation, a region of greater density was indicated $51,52,29$. The more inclined and resistant the rock, the less permeable. Thus, the analyses allowed the region of the samples that were more porous to be evaluated. The analyses resulted in more accurate estimates of microscopic changes as well as an understanding of how the dissolution of bonds between grains led to macroscopic changes. Such macroscopic changes include loss of strength and mechanics causing irreversible damage to the rock, as observed in the experimental results of ${ }^{21}$.

\section{b. Analysis of induced fractures before and after degradation via $\mu$ CT}

Another analysis conducted using the $\mu \mathrm{CT}$ images was the qualitative study of an induced fracture in the rock. The degradation procedure was the same as that performed on samples without a fracture, and a comparative study of the fracture was conducted before and after the procedure. The purpose of this analysis was to understand the impact of exposure to an acidic fluid on a fractured geomaterial, which was a preferential path for the injected fluid. In Figure 23, the structure of the studied sample is shown; the fracture was located throughout the diameter and length of the sample. If the sample were torn in half, one face would be $35.20 \mathrm{~mm}$ and the other $34.80 \mathrm{~mm}$. The surface profile of the fracture was irregular.

Na comparação da Figura 24, é notável que apesar do aumento dos poros ser considerável, a ampliação da porosidade se concentra na fratura, uma vez que se torna o caminho preferencial do fluxo. Even with this preferential path, the increase in the number of pores throughout the sample was evident. Preferential paths are also studied in wells, where this effect can be associated with an injection of a reactive fluid. When this happens, there is an increase in porosity in the well, as well as a significant increase in the opening of the well due to the dissolution of soluble minerals. The rock structure close to the well may also be affected. 
During the reconstruction of the 3D structure of the rocks, the fracture surface was analyzed before and after the passage of the fluid. This analysis is represented in Figures $25 \mathrm{a}$ and $25 \mathrm{~b}$, which show significant increases in the number of pores and in the fracture.

Figures $25 \mathrm{c}$ and $25 \mathrm{~d}$ present an interpretation of the distribution of significant voids in the samples. Before the passage of fluid, only the fracture at the beginning of the sample was visible. Thus, the fracture was irregular in terms of thickness throughout the sample, having a larger opening at its end compared to the opening at the middle of the sample. Because the opening in the middle of the sample was small, it favored an intact structure. In the analysis after the passage of the fluid, the surface structure of the fracture was visible, both at the end and at the center of the sample.

This procedure was related to the analysis of pore size, in which very small pores (less than $0.1 \mathrm{~mm}$ ) were omitted from the image. When Figure 25a is correlated with Figure 25c, pores with thicknesses from 0.1 $\mathrm{mm}$ are visible, and they are even more evident in the fracture region. In Figure 25d, the pores are more apparent, due to the increase in pore size. However, only those pores with larger dimensions were counted, so there is no way to count the number of pores using this analysis method. To count the increase in the thickness of the fracture, which the dissolution of minerals provided mainly the increase in the fracture opening, by the fracture induce a preferential fluid path.

For a better understanding of the influence of the acid injection process on the fracture, quantification of the fracture opening along the sample was performed before and after the passage of fluid. There was an increase of about $82 \%$ in the fracture opening area throughout the sample (Table 5).

The purpose of this analysis was to highlight the advantages of CT image analysis since it is possible to visualize, determine, and quantify the changes that occur in rocks.

\section{Conclusions}

Non-destructive 3D visualization analysis of the interior of porous material samples is the main contribution that $\mathrm{X}$-ray microtomography provides to petrographic and microstructural studies. Considerable information obtained from petrographic analysis by optical microscopy cannot be reproduced by microtomography analysis. Thus, microtomography is an effective tool in the scope of sample characterization. Analysis of the internal structure of samples via $\mu C T$ and $3 D$ reconstruction of tomography images has been increasing in popularity. According to ${ }^{53}$, these techniques successfully provided the internal characteristics in similar samples under similar conditions by coupled hydromechanics (i.e., hydromechanics and chemistry).

In addition to 2D analysis, the 3D structure of the pores of the samples before and after injection with fluid was evaluated. The maximum increase in porosity was quantified from $11.8 \%$ to $41.3 \%$ and $31.6 \%$ to $52 \%$, respectively. The values of porosity determined in the laboratory and via $\mu \mathrm{CT}$ image estimation were compared and revealed that rock porosity estimations were more effective using the $\mu \mathrm{CT}$ method. The $\mu \mathrm{CT}$ technique considers the entire sample structure and is a non-destructive procedure. The 
proposed method quantified the pores according to their area and expressed this information as the pore orientation, providing additional information about the flow's preferential path. The results of this analysis showed a direct relationship with the obtained reference porosities and, using this methodology, the fracture of the sample was characterized before and after dissolution.

The extraction and injection of fluids at high depths increase mechanical and physical risks due to mineral dissolution as well as changes in pressure, temperature, and saturation that affect the stress state of the reservoir rock. Thus, the analysis of characteristics via microscopic structures is a relevant engineering tool. The conditions to which the rocks are subjected are reflected in the reservoir's acidification processes, such as geological storage of $\mathrm{CO}^{2}$ and advanced oil or gas recovery, which pose negative consequences for the material

\section{Declarations}

\section{DATA AVAILABILITY}

All data included in this study are available upon request by contact with the corresponding author.

\section{ACKNOWLEDGMENT}

The authors acknowledge the financial support from PETROBRAS.

\section{RECOMMENDATIONS}

For future research, it is suggested to produce new carbonatic synthetic rocks, for physical and mechanical characterization.

ADDITIONAL INFORMATION

Correspondence and requests for materials should be addressed to Katia Galindo.

\section{References}

1 duliu o. 1999. Computer axial tomography in geosciences: an overview. Earth science reviews, 48:265281.

2 cnudde v., masschaele b., dierick m., vlassenvroeck j., hoorebeke l.v., jacobs p. 2006. Recent progress in $\mathrm{x}$-ray ct as a geosciences tool. Applied geochemistry, 21:826-832.

3 neto, j. M. R., fiori, a. P., lopes, a. P., marchese, c. , coelho, c. V. P., vasconcellos, e. M. G., silva, g. F. \& secchi, r. (2011) computerized $x$-ray microtomography integrated with petrography in the threedimensional study of porosity in rocks. Revista brasileira de geosciences.,41(3): 498-508, september 2011 
4 denison, c., carlson, w.d. three-dimensional quantitative textural analysis of metamorphic rocks using high-resolution computed x-ray tomography: part ii. Application to natural samples j. Metamorph. Geol., 15 (1997), pp. 45-57, 10.1111/j.1525-1314.1997.00007.x

5 kahl, n., dilissen, w.-a., hidas, k., garrido, c.j., lópez-sánchez vizcaíno v., román-alpiste, m.j. 3-d microstructure of olivine in complex geological materials reconstructed by correlative $x$-ray $\mu$-ct and ebsd analyses j. Microsc., 268 (2) (2017), pp. 193-207, 10.1111/jmi.12598

6 ketcham r., slottke, d.t., j.m. sharpthree-dimensional measurement of fractures in heterogeneous materials using high-resolution x-ray computed tomography geosphere, 6 (2010), pp. 499-514, $10.1130 /$ ges00552.1

7 schmitt m., halisch m., müller c., peres-fernandes c. . Classification and quantification of pore shapes in sandstone reservoir rocks with 3-d x-ray micro-computed tomography solid earth, 7 (2016), pp. 285-300, $10.5194 /$ se-7-285-2016

8 lai wang, g., fan z., chen j., qin z., xiao c., wang s., x. Fanthree-dimensional quantitative fracture analysis of tight gas sandstones using industrial computed tomography sci. Rep., 7 (2017), p. 1825, 10.1038/s41598-017-01996-7.

9 latief, f., irayani, z. \& fauzi, u. (2012) resolution dependency of sandstone's physical properties. In annual $\mu$ ct user meeting. Bruker, belgium.

10 mikko voutilainen, miettinen a., sardini p., parkkonen j., gylling j. S., björn, selroos j., yli-kaila m., lasse k., siitari-ka. M., characterization of spatial porosity and mineral distribution of crystalline rock using x-ray micro computed tomography, c-14-pmma autoradiography and scanning electron microscopy, applied geochemistry, volume 101, 2019, pages 50-61, issn 0883-2927,

11 austad, t. Et al (2008). Seawater in chalk: an eor and compaction fluid. Society of petroleum engineers. Doi:10.2118/118431-pa.

12 korsnes, r.i.; madland, m.v., vorland, k.a.n, hildebrand-habel, t., kristiansen, t.g.,hiorth, a. Enhanced chemical weakening of chalk due to injection of co2 enriched water. $29^{\circ}$ international symposium of the society of core analysts, abu dhabi. Pp. 1-12, 2008.

13 ciantia mo, castellanza r, crosta gb, hueckel t (2015) efects of mineral suspension and dissolution on strength and compressibility of soft carbonate rocks. Eng geo/ 184:1-18.

14 penghui zhang, yong il lee, jinliang zhang a review of high-resolution x-ray computed tomography applied to petroleum geology and a case study. micron, 124 (2019), p. 102702, 10.1016/j.micron.2019.102702

15 yang, f. Zhou, h. Zhang, c., jingjing lu, lu, x. Geng, y. An analysis method for evaluating the safety of pressure water conveyance tunnel in argillaceous sandstone under water-weakening conditions, 
tunnelling and underground space technology, volume 97, 2020.

16 galindo, k. B. T.; lins, c. M. M. S.; lima, a.; guimaraes, I.j.n.; silva, k. C. L. (2019) hydro-mechanic behavior of synthetic carbonate rocks subjected to injection of a reactive fluid. In: 53rd us rock mechanics / geomechanics symposium held, new york, new york. 53rd us rock mechanics / geomechanics symposium held in new york, new york usa, 2019.

17 oliveira, s. M. F. Estudo do comportamento geomecânico e químico das fraturas de rochas carbonáticas. Tese de doutorado. Department of civil engineering, federal university of pernambuco, pernambuco, brazil. 2019.

18 cunha, a. R.; moreira, a. C.; kronbauer, d. P.; mantovani, i. F.; fernandes, c. P. Determinação de propiedades petrofísicas de rochas via simulação: um camino interdisciplinar. Revista brasileira de ensino de física. V. 34, n. 4, 2012.https://doi.org/10.1590/s1806-11172012000400015.

19 belila, a. M. P.; kuroda, m. C.; souza, j. P. P.; vidal, a. C.; trevisan, o. V. Petrophysical characterization of coquinas from morro do chaves formation (sergipe-alagoas basin) by x-ray computed tomography. Revista do instituto de geociências - usp. Geol. Usp, sér. Cient., são paulo, v. 18, n. 3, p. 3-13, setembro 2018. Doi: 10.11606/issn.2316-9095.v18-124101.

20 lu, db., wang, f., chen, xd. Et al. An improved ert approach for the investigation of subsurface structures, (2017). Pure appl. Geophys. 174: 375. Https://doi.org/10.1007/s00024-016-1386-9.

21 galindo, k.; guimarães, I. Lins, c.; lima, a.; santos, y. Gomes, i. Minerals dissolution effect on the mechanical properties of synthetic carbonatic rocks under a reactive fluid injection. American scientific research journal for engineering, technology, and sciences (asrjets). Vol 79 no 1 (2021) 2313-4402.

22 fernandes, j. S.; appoloni, c. R.; fernandes, c. P. Determinação de parâmetros microestruturais e reconstrução de imagens 3-d de rochas reservatório por microtomografia de raios $\mathrm{x}$. Recen-revista ciências exatas e naturais, v. 11, n. 1, p. 35-47, 2010.

23 ketcham, r.a; calrson, w.d. acquisition, optimization and interpretation of x-ray computed tomographic imagery: applications to the geosciences comput. Geosci., 27 (2001), pp. 381-400.

24 schneider, c.a; rasband, w.s; eliceiri, k.w. nih image to imagej: 25 years of image analysis nat. Methods, 9 (7) (2012), pp. 671-675.

25 cnudde, v., boone, m.n. high-resolution x-ray computed tomography in geosciences: a review if the current technology and applications earth sci. Rev., 123 (2013), pp. 1-17.

26 fusseis, f. , steeb, h. , xiao, x. , zhu, . Butler, i.b. , elphick, mäder, s. U. A low-cost x-ray transparent experimental cell for synchrotron-based $x$-ray microtomography studies at geological reservoir conditions j. Synchrotron radiat., 21 (2014), pp. 251-253. 
27 du plessis a, olawuyi bj, boshoff wp, le roux sg. Simple and fast porosity analysis of concrete using $x-$ ray computed tomography. Materials and structures. 2016;49(1):553-562.

28 janesick, j. R. Scientific charge-coupled devices spie press, bellingham, wa, 2001.

29 costa, larissa fernandes et al. Espaço poroso em solos brasileiros usando tomografia computadorizada de raios-x (porous space in brazilian soils using x-ray computed tomography). Revista brasileira de geografia física, v. 9, n. 3, p. 692-706, 2016.

30 higo, yosuke; morishita, ryoichi et al. Local water-retention behaviour of sand during drying and wetting process observed by micro $x$-ray tomography with trinarisation. Japanese geotechnical society special publication, the japanese geotechnical society, v. 2, n. 16, p. 635-638, 2016.

31 higo, yosuke; oka, fusao et al. Trinarization of $\mu \mathrm{x}$-ray ct images of partially saturated sand at different water-retention states using a region growing method. Nuclear instruments and methods in physics research section b: beam interactions with materials and atoms, elsevier, v. 324, p. 63-69, 2014.

32 tarquis, am et al. Pore network complexity and thresholding of $3 \mathrm{~d}$ soil images. Ecological complexity, elsevier, v. 6, n. 3, p. 230-239, 2009.

33 jefferies, daniel a et al. Characterizing soil surface structure in a temperate treebased intercropping system using x-ray computed tomography. Agroforestry systems, springer, v. 88, n. 4, p. 645-656, 2014.

34 evans em. The treatment of trochanteric fractures of the femur. $J$ bone joint surg $\mathrm{br}$ 1949;31b(02):190-203

35 zdilla, m. J.; hatfield, s. A.; mclean, k. A.; cyrus, I. M.; laslo, j. M.; lambert, h. W. Circularity, solidity, axes of a best fit ellipse, aspect ratio, and roundness of the foramen ovale: a morphometric analysis with neurosurgical considerations. The journal of craniofacial surgery, v. 27, p. 222-228, 2016.

36 espindola, w. R., nascente, e. De p., urzêda, m., teodoro, j. V. Da s., gonçalves, g. B., castro, r. D. De, martins, m. E. P., \& souza, w. J. De. (2020). Quality of refrigerated raw milk produced in the microregion of pires do rio, goiás, brazil. Research, society and development, 9(7), e153973958.

Https://doi.org/10.33448/rsd-v9i7.3958

37 navarro, f.c.; artur, a.c. características petrográficas como ferramenta para a previsão do comportamento físico e mecânico de granitos ornamentais: uma discussão. Anais iii simpósio de rochas ornamentais do nordeste. Recife, pernambuco. Pp.2-9, 2002.

38 lins, c.m.m.s, guimarães, l., lima a., gomes, i. (2015). Numerical and experimental analysis of horizontal stress changes and soil collapse during chemical dissolution in a modified oedometer cell. International journal of geotechnical and geoenvironmental engineering, soils and rocks. V.39, n. 1, p 4-12, january 2015.lucia, f.j.; kerans, c.; jennings jr., j.w. 2003. Carbonate reservoir characterization. Journal of petroleum technology, 55(6):70-72. Spe-82071.

Page 16/25 
39 scholle, p.a. \& ulmer-scholle, d.s (2003). A color guide to the petrography of carbonate rocks, grains, textures, porosity, diagenesis, aapg memoir 77, p. 212.

40 amieux, p.; bernier, p.; dalongeville, r.; medwecki, v. Cathodoluminescence of carbonate-cemented holocene beachrock from the togo coastline (west africa): an approach to early diagenesis. Sedimentary geology, v. 65, p. 261-272, 1989.

41 geet m.v., swennen r., wevers m. 2000. Quantitative analysis of reservoir rocks by microfocus x-ray computerized tomography. Sedimentary geology, 132:25-36.

42 wildenschild d., hopmans j.w., vaz c.m.p., rivers m.l., ricard d., christensen b.s.b. 2002. Using x-ray computed tomography in hydrology: systems, resolutions and limitations. Journal of hydrology, 267:285297.

43 kate, j. M., and c. S.gokhale (2006), a simple method to estimate complete pore size distribution of rocks, eng. Geol., 84(1-2), 48-69.

44 appoloni c.r., fernandes c.p., rodrigues c.r.o. 2007. X-ray microtomography of a sandstone reservoir rock. Nuclear instrume nts and methods in physics research a, 580:629-632. Detectors and associated equipment, volume 580, issue 1, 2007, pages 629-632,issn 0168-9002, https://doi.org/10.1016/j.nima.2007.05.027.

45 cnudde v., silversmit g., matthieu b., jan d., björn d.s., schoonjans t., denis v.l., yoni d.w., marlina e., laszlo v., luc v.h., patric j. 2009. Multi-disciplinary characterization of a sandstone crust. Science of the total environment, 407:5417-5427.

46 flukiger f. \& bernard d. 2009. A new numerical model for pore scale dissolution of calcite due to co2 satured water fl ow in 3d realistic geometry: principles and fi rst results. Chemical geology, 265:171-180.

47 long h., swennen r., foubert a., dierick m., jacobs p. 2009. 3d quantifi cation of mineral components and porosity contribuition in westphalian c sandstone by microfocus $\mathrm{x}$-ray computed tomography. Sedimentary geology, 220:126-125.

48 tsakiroglou c.d., loannidis m.a., amirtharaj e., vizika o. 2009. A new approach for the characterization of the pore structure of dual porosity rocks. Chemical engineering science, 64:847-859.

49 izgec o., zhu d., hill a.d. 2010. Numerical and experimental investigation of acid wormholing during acidization of vuggy carbonate rocks. Journal of petroleum science and engineering, 74:51-66.

50 geet m.v. \& swennen r. 2001.quantitative $3 d$-fracture analysis by means of microfocus $x$-ray computer tomography ( $\mu \mathrm{ct})$ : an example from coal. Geophysical research letters, 28(17):3333-3336.

51 geet m.v., \& swennen r. 2001.quantitative 3d-fracture analysis by means of microfocus x-ray computer tomography ( $\mu \mathrm{ct})$ : an example from coal. Geophysical research letters, 28(17):3333-3336. 
52 higo, yosuke; oka, fusao et al. Trinarization of $\mu \mathrm{x}$-ray ct images of partially saturated sand at different water-retention states using a region growing method. Nuclear instruments and methods in physics research section b: beam interactions with materials and atoms, elsevier, v. 324, p. 63-69, 2014.

53 kou, m., liu, x., tang, s., wang, y., 3-d x-ray computed tomography on failure characteristics of rock-like materials under coupled hydro-mechanical loading, theoretical and applied fracture mechanics, volume 104, 2019, 102396, issn 0167-8442, https://doi.org/10.1016/j.tafmec.2019.102396.

\section{Tables}

Table 1: Percentages of materials used in synthetic rocks.

\begin{tabular}{|llll|}
\hline \multicolumn{3}{|l|}{ Fraction (\%) } \\
\hline Calcite & Sand & Cement & Water \\
\hline 68 & 3,6 & 28 & 20 \\
\hline
\end{tabular}

\section{Reference: 21.}

Table 2: Physical and mechanical characteristics of the samples.

\begin{tabular}{|lllll|}
\hline$e$ & $\varnothing(\%)$ & UCS $\sigma c(\mathrm{MPa})$ & $\sigma(\mathrm{MPa})$ & $E(\mathrm{GPa})$ \\
\hline 0,58 & 36,8 & 11,74 & 0,33 & 0,313 \\
\hline
\end{tabular}

Reference: 21 .

Table 3: Comparison of porosity values.

\begin{tabular}{|lll|}
\hline Method & Test & $\varnothing(\%)$ \\
\hline 3D Micro Tomography & Before Acidification & 31,0 \\
\hline & After Acidification & 52,0 \\
\hline 2D Micro Tomography & Before Acidification & 11,8 \\
\hline Lab & After Acidification & 41,3 \\
\hline & $\begin{array}{c}\text { Before Acidification } \\
\text { After Acidification }\end{array}$ & 36,8 \\
\hline
\end{tabular}

Table 4: Behavior of porosity distribution by particle size. 


\begin{tabular}{|lllll|}
\hline Samples & \multicolumn{2}{l|}{ Pore distribution $(\%)$} & & \\
\cline { 2 - 5 } & Image dimensions $\left(\mathrm{x}^{*} \mathrm{y} \mathrm{z}^{\mathrm{z}} \mathrm{z}\right)$ & Small pores & Medium pores & Large \\
& & & & pores \\
\hline Before Acidification & $(948 * 1128 * 1311)$ & 0,094 & 0,723 & 23,279 \\
\hline After Acidification & $(948 * 1128 * 1070)$ & 0,0067 & 0,027 & 48,967 \\
\hline
\end{tabular}

Table 5: Determination of fracture area before and after degradation.

\begin{tabular}{|lllll|}
\hline Sample & Fracture size (pixels) & \multicolumn{3}{c|}{ Fracture size $(\mathrm{mm})$} \\
\cline { 3 - 5 } & & Top & Middle & Botton \\
\hline CC - Before Acidification & 0,496 & 0,56 & 0,17 & 0,1 \\
\hline CC - After Acidification & 2,797 & 3,96 & 2,43 & 2,22 \\
\hline
\end{tabular}

\section{Figures}

Figure 1

Halimeda grains, shell fragments, and reefs. 

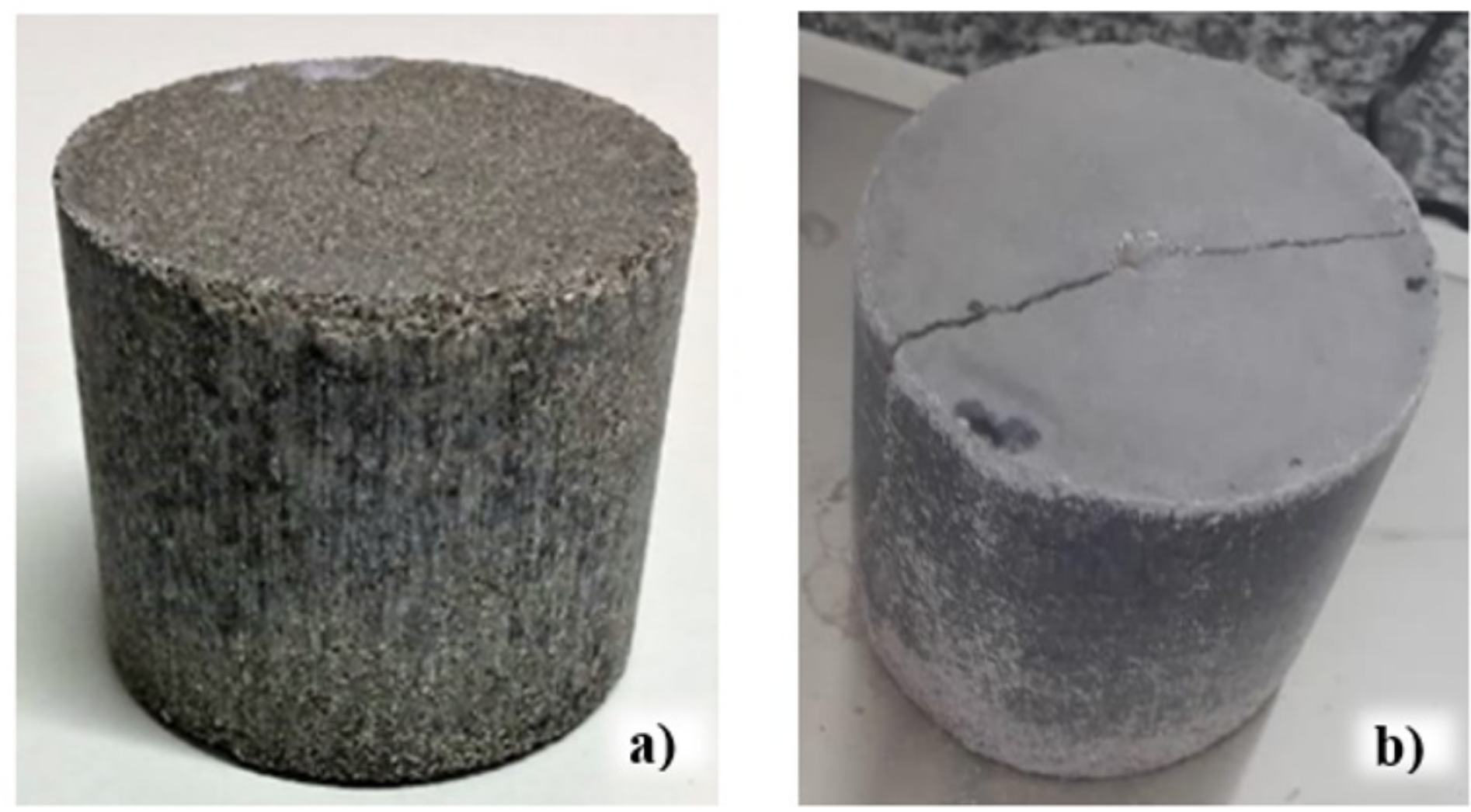

Figure 2

Synthetic carbonate samples. (a) Intact rock and (b) fractured rock.

\section{Figure 3}

Illustrative diagram summarizing the steps in the acquisition of X-ray microtomography images.

\section{Figure 4}

Microtomography equipment from the DEN laboratory. (a) View inside the equipment and (b) View of the software. 


\section{Figure 5}

Binarization of CT image slices, (a) original image and (b) binarized image.

\section{Figure 6}

Representation of the ellipse allocation method to obtain orientation properties.

\section{Figure 7}

Representation of ellipses for the morphological analysis of each pore. (a) Image of the sample with binarization and (b) enlarged image to better visualize the ellipses in the pores.

Figure 8 
Microscopy procedure using thin slides. (a) Thin slides and (b) petrographic microscope.

Figure 9

A) Edometric cell diagram comprised of (a) upper, (b) lower, and (c) sample confinement rings and (d) piston for vertical load application. B) Modified edometric cell, highlighting the strain gauge in the confinement ring and the LVDT in the upper part of the cell.

Reference: Modified 38; 21.

Figure 10

Schematic of the dissolution test experimental apparatus.

Reference: 21.

Figure 11

General aspects observed in the Dino-Lite Pro Lupa. (a) Faceted quartz grains (red arrow) and round grains related to potential minerals of the oxide group (rutile, ilmenite, and magnetite - orange arrow) and (b) carbonatic skeletal grains interpreted as bivalve carapaces (blue arrow).

Figure 12

Synthetic carbonate rock observed under the petrographic microscope. Detail of green algae fragment Halimeda (lower blue arrow) and a bivalve carapace (upper blue arrow). Quartz grain (red set) and (b) 
quartz grains in a pore region (black region, red arrow).

Figure 13

Image obtained from cathodoluminescence. (a) Detail for the Halimeda algae fragments showing red luminescence (blue arrow) and fine grains of quartz or feldspar showing a blue luminescence (red arrow). (b) Binding cement represented by punctual luminescence located in the matrix of the synthetic rock.

Figure 14

Micrograph obtained using a petrographic microscope (Nikon Eclipse POL) at parallel nicols of the samples (a) before and (b) after degradation, as well as calcium carbonate skeletal grains of a gastropod (red arrow - carbonate skeletal grain; green arrow - porosity; blue arrow - quartz grain).

Figure 15

Micrograph obtained using a petrographic microscope (Nikon Eclipse POL) of crossed nicols of the synthetic carbonate rock (a) before and (b) after degradation, as well as the Halimeda green algae fragment (lower blue arrow) and a bivalve carapace (upper blue arrow).

Figure 16

Images (obtained using a petrographic microscope, Nikon Eclipse POL) of the petrographic slide of the cement sample after degradation with longer exposure to acidic fluid, emphasizing the increase in intraparticle porosity. (a) Micrograph at parallel nicols (light green arrow - intra-particle porosity; red arrow - carbonate grain; yellow arrow - quartz grain). Enlarged image to more clearly display intraparticle porosity. (b) Micrograph of crossed nicols showing calcium carbonate skeletal grain of a gastropod (blue arrow - carbonate skeletal grain; green arrow - porosity; red arrow - rounded grain of quartz; lilac arrow - cement). (c) Micrograph at parallel nicols showing changes in the structure of quartz grains after degradation (pink arrow). 
Figure 17

2D analysis of the samples' tomography images. (a) Before rock degradation, (b) after rock degradation, (c) identification of pores within the rock matrix before degradation, and (d) identification of pores within the rock matrix after degradation.

Figure 18

3D structure of the sample's solid matrix with cuts of the sample slices from the central area (a) before degradation and (b) after degradation.

Figure 19

3D structure of the (a) predegradation rock pore arrangement and (b) post-degradation sample pores.

Figure 20

While analyzing pore arrangement before acidification, pore conduct was uniform. (a) Before degradation and (b) after degradation.

Figure 21

Accumulated pore frequency depending on the area (a) before degradation and (b) after degradation. 
Figure 22

Analysis of pore orientation on the xy-axis (a) before degradation and (b) after degradation.

Figure 23

Disposition of the fracture in the sample. (a) 3D sample structure and (b) 3D sample structure with $50 \%$ transparency.

Figure 24

3D structure of the solid matrix of the fractured sample (a) before degradation and (b) after degradation. Comparison of pore arrangement and fracture opening of the specimen (c) before and (d) after degradation. (e) Fracture length and depth along the specimen represented by the red dashed and black dashed lines, respectively.

Figure 25

2D comparison of sample opening (a) before and (b) after degradation. Fracture opening distribution along the sample (c) before and (d) after degradation. 